\title{
Mass Transfer and Fluid Hydrodynamics in Sealed End Hydrophobic Hollow Fiber Membrane Gas-liquid Contactors
}

\author{
S. Kartohardjono ${ }^{1} \&$ V. Chen $^{2}$ \\ ${ }^{1}$ Department of Chemical Engineering University of Indonesia \\ Kampus Baru UI Depok 16424, Indonesia. \\ ${ }^{2}$ School of Chemical Engineering and Industrial Chemistry \\ University of New South Wales, Sydney 2052, Australia. Email: v.chen@unsw.edu.au
}

\begin{abstract}
Hollow fiber membrane modules have been extensively used as gas-liquid contactor devices to provide a high surface area within a small volume. Hollow fiber membrane contactors have been demonstrated in a wide range of application such as in gas stripping and gas absorption. In this study the performance of sealed end hydrophobic microporous hollow fiber membranes contactors were evaluated to remove dissolved oxygen from water via vacuum degassing process. Hollow fibers membranes used in the experiment were hydrophobic microporous polypropylene of $650 \mu \mathrm{m}$ in outer diameter, $130 \mu \mathrm{m}$ wall thickness and nominal pore size of $0.2 \mu \mathrm{m}$. Based on the experimental result the sealed end membrane contactor can remove oxygen from water as high as 3.4-gram oxygen per square meter of membrane area per hour. The oxygen flux decreases with increasing module-packing density for the same water velocity. The same effect also occurred for the mass transfer coefficient of the membrane contactors. The mass transfer coefficients were independent of fiber length within the range of study. Hydrodynamics analysis of the contactors showed that at the same Reynolds number pressure drops increase with increasing packing density due to an increase in friction between fibers and water.
\end{abstract}

Keywords : Hollow fiber; contactor; hydrophobic; mass transfer

\subsection{INTRODUCTION}

Hollow fiber membrane modules have been widely used as contactor and filtration devices to provide high surface area in a small volume. As a gas-liquid contactor, unlike more conventional membrane applications such as microfiltration, ultrafiltration and reverse osmosis, the driving force for separation is a concentration rather than a pressure gradient. Therefore, only a small pressure drop across the membrane is required to ensure that gas-liquid interface is remain immobilized at the membrane pores.

Membrane-based contactor devices provide an alternative technology for gas-liquid contacting operations that overcomes disadvantage of conventional contactors such as columns and towers,

*Correspondence: S. Kartohardjono (Email: sutrasno_k@yahoo.com.au) 
and in the same time offers substantially more interfacial area using a suitable membrane configuration or module such as hollow fiber membrane modules. In hollow fiber membrane contactors, gas flow rate and liquid flow rate can be varied independently of each other without flooding, loading and foaming, which are characteristics of dispersion-based gas-liquid contactors. Furthermore, all of the membrane surface area is available for contacting regardless of how low the flow rates are. Membranebased contactors are easier to be scaled-up than other conventional mass transfer equipment. Membrane operations usually scale linearly, so that an increasing in capacity is achieved simply by the add of membrane modules subject to the limitations of supporting equipment such as transfer pump, piping, etc. In addition, membrane-based contactors can be operated over a wide range of capacities by modular design. Small or large capacities can be obtained by using few or many modules.

The disadvantages of membrane systems are the additional resistance of membrane it self to mass transfer performance, subject to channeling which result in a loss efficiency, and subject to fouling. Membrane systems have a short life and a limitation in the number of equilibrium stages due to pressure drop constraints. These relatively few disadvantages are often compensated by the advantages cited above [1].

Hollow fiber membrane contactors (HFMC) have been demonstrated in a wide range of application such as in gas stripping and gas absorption [2]. In the hydrophobic microporous membrane gas/ liquid contactors, the pores are filled with gas and as a result the resistance in the membrane can be neglected to the overall resistances of the contactor. This behavior of hydrophobic membrane contactor has brought many researchers to utilize hydrophobic microporous hollow fiber membrane contactors to remove oxygen from water [3].

There are many production areas related with oxygen-water system such as semiconductors, pharmaceuticals, foods and power, which need oxygen-free water. Dissolved oxygen has to be removed from water for many reasons depend on the application area. In the power industry, for instance, corrosion in a boiler or steel pipes will be prevented if the dissolved oxygen level in the water is lower than $0.5 \mathrm{mg} / \mathrm{L}$ [4]. In the semiconductor industry, dissolved oxygen concentration must be reduced to a few parts per billion $\left(\mathrm{mg} / \mathrm{m}^{3}\right)$ to avoid uncontrolled native silica oxide growth in water-immersion system [5].

The mass-transfer performance in the hollow fiber membrane gas/liquid contactors depends on the fiber membranes and module, the fluids properties, the flow characteristics in the module and the flow media employed [1]. This paper studied the performance of sealed end hydrophobic microporous hollow fiber membranes contactors to remove dissolved oxygen from water via vacuum degassing process. The objectives of this study are:

(i) To evaluate the effectiveness of sealed end hydrophobic microporous polypropylene hollow fiber membrane contactors in removing dissolved oxygen from water at various packing density from $1 \%$ to $52 \%$.

(ii) To develop a simple model to characterize the mass transfer performance in the contactors,

(iii) To evaluate fluid hydrodynamics in the membrane contactors.

\section{0 THEORY}

A detailed of mass transfer coefficients in the fiber lumen and the shell of hollow fiber module, as well as in the membrane, is necessary for design purpose of gas-liquid contactors. The description of gas/liquid transport through microporous membranes usually based on the film model, that is, it assumes a sequence three steps depend on the process applied. 
The mass transfer of dissolved oxygen from water on the shell-side to the gas side in the lumen fiber of membrane gas/liquid contactor involves three steps: transfer of oxygen in water, diffusion of oxygen through the membrane, and diffusion of oxygen into the gas stream. The driving force for the oxygen transfer in vacuum degassing process is the concentration gradient of oxygen in the liquid phase and in the gas phase, which is in vacuum condition. There are three resistances in series determine the mass transfer of gas across the membrane and are composed of a resistance across the liquid film layer $\left(1 / k_{l}\right)$, the membrane resistance $\left(1 / k_{m}\right)$ and a resistance across the gas film layer $\left(1 / H k_{g}\right)$. The sum of these resistances is the overall resistance for gas transfer in a membrane contactor system which correspond to the mass transfer coefficient as expressed in Equation (1):

$$
\frac{1}{K}=\frac{1}{H k_{g}}+\frac{1}{k_{m}}+\frac{1}{k_{l}}
$$

Since the mass transfer resistance in the gas phase is negligible, the diffusion of oxygen in the liquid phase becomes the rate-determining step and Equation (1) can be reduced to Equation (2),

$$
\frac{1}{K}=\frac{1}{k_{l}}
$$

The correlation to describe the mass transfer performance is very important in designing membrane contactors and is often described by an empirical correlation. The obvious variables that contribute to overall mass transfer are velocity $v$, viscosity $\mu$, density $\rho$, mass diffusivity $D$, module diameter $d_{p}$ and mass transfer coefficient in a liquid phase $k_{l}$. Generally, mass transfer coefficients for mass transfer devices including membrane contactors can be expressed in the form of Equation (3).

$$
S h \propto R e^{\alpha} S c^{\beta} f(\text { geometry })
$$

$S h, R e$ and $S c$, which are dimensionless numbers, are the Sherwood number, the Reynolds number and the Schmidt number, respectively, and $f$ (geometry) is some function of geometry such as $d_{e} / l$, and packing density [1]. From studies of fluid mechanics and heat transfer, it has been shown that the Sherwood number for mass transfer is analogous to the Nusselt number used in convective heat transfer. Furthermore, the Schmidt number bears the same relationship to momentum and mass transfer as the Prandtl number does to momentum and heat transfer. The Sherwood, Reynolds and Schmidt numbers are defined by:

$$
\begin{gathered}
S h=k_{l} \frac{d_{e}}{D} \\
R e=\frac{\rho v d_{e}}{\mu} \\
S c=\frac{\mu}{\rho D}
\end{gathered}
$$

$d_{e}$ is the equivalent diameter of the membrane module and is defined as:

$$
d_{e}=4 \frac{\text { cross }- \text { sectional area }}{\text { wetted perimeter }}=\frac{d_{p}^{2}-n d_{f}^{2}}{d_{p}+n d_{f}}
$$

where $d_{p}, d_{f}$ and $n$ are module diameter, fiber diameter and number of fibers in the module, respectively. 
The Reynolds number characterizes fluid flow as ratio of inertial-to-viscous forces, while the Schmidt number expresses the relationship between momentum diffusivity and molecular diffusivity. The exponent of Reynolds number, $\alpha$, in Equation (3) is an indication of mass transfer regime, where the higher the $\alpha$, more turbulence the mass transfer regime is. For instance, for laminar mass transfer with fully developed velocity profile and developing concentration profile, $\alpha=0.33$. For developing velocity and concentration profiles, i.e. entry region conditions $\alpha=0.5$, while for turbulent mass transfer the value of $\alpha$, approaching 0.8 to1 [6].

The frictional loss for a fluid flowing through the shell side of the hollow fiber membrane module can be calculated in the normal manner by considering the mean hydraulic diameter of the system. Basically, the pressure drop equation was firstly used in shell and tube heat exchanger. Ahmed et al. [7] suggested that there are several energy loss mechanisms in the membrane module:

(i) loss due to friction between the water and the fibers,

(ii) loss due to friction between the water and the module housing,

(iii) loss due to entrance and exit of water from the module, and

(iv) loss due to expansion and contraction.

Friction factors of the modules can be calculated using equation:

$$
f=\frac{\Delta P d_{e}}{2 l \rho v_{i}^{2}}
$$

where $f$ is the friction factor of the module, $\Delta P$ is the water pressure drop, $d_{e}$ is the equivalent diameter of the module, $l$ is module length, $\rho$ is the water density, and $v_{l}$ is the water velocity, respectively.

\subsection{EXPERIMENT}

Hollow fibers membranes used in the experiment were hydrophobic microporous polypropylene of MEMCOR CMF-S S10T supplied by MEMCOR Australia. The fibers are $650 \mu \mathrm{m}$ in outer diameter, $130 \mu \mathrm{m}$ wall thickness and with nominal pore size of $0.2 \mu \mathrm{m}$. The hollow fiber modules were made by potting one end of the fibers into $1.5 \mathrm{~cm}$ nipple using epoxy (Araldite ${ }^{\circledR}$ ) and the other end of the fibers were heat-sealed. The module was connected to external shell made from PP pipe with a PP T-joint, and at the other end of the nipple was connected to vacuum pump using brass reducer 1.5 to $0.3 \mathrm{~cm}$. The diameter of the external shell can be varied using appropriate connection to PP T-joint where in this study $0.8,1.2,1.4,1.6$ and $1.9 \mathrm{~cm}$ shell diameter were used. There were 18 sealed end modules used in the experiment. In the sealed end modules, the fibers were individually sealed and occupied $1.65-52.81 \%$ of the cross-sectional area of the shell.

Schematic of experimental configuration as shown in Figure 1 was used to measure mass transfer performance and pressure drop of the membrane modules. The water in the reservoir was initially saturated with oxygen from air prior to each experiment. The mass balance on the reservoir in the experiments in a steady-state condition can be described as [8]:

$$
\ln \frac{C_{t}}{C_{0}}=\frac{Q_{l}}{V}\left(\exp \left(-K a \frac{l}{v_{l}}\right)-1\right) t
$$

Meanwhile, overall mass transfer coefficient can be calculated by Equation (10). 


$$
K=-\frac{v_{l}}{a l} \ln \left(\operatorname{slope} \frac{V}{Q_{l}}+1\right)
$$

Equation (9) and (10) were used for the analysis flux of oxygen through the membrane and mass transfer coefficients based on the experimental data. The value of slope is derived from Equation (10) and can be expressed as:

$$
\text { slope }=\frac{Q_{l}}{V}\left(\exp \left(-K a \frac{l}{v_{l}}\right)-1\right)
$$

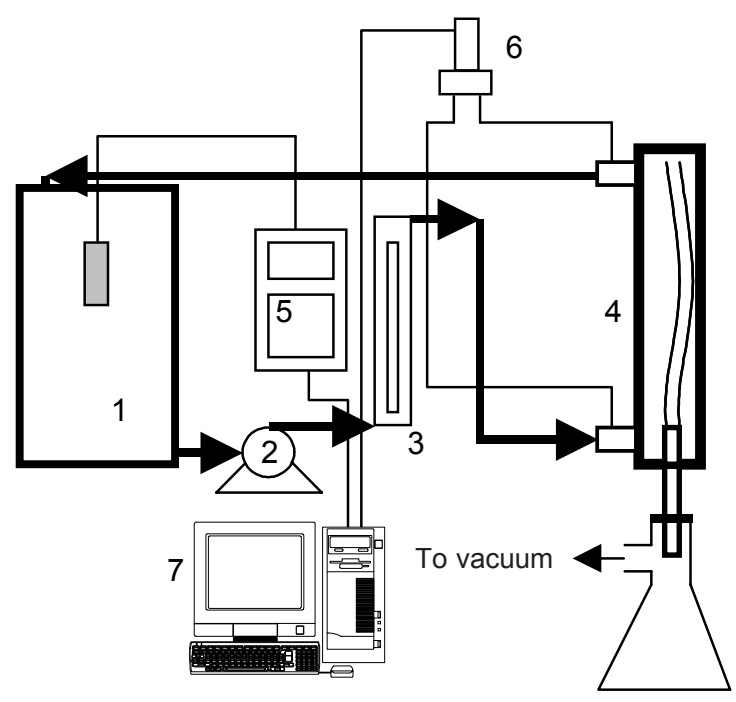

Figure 1 Schematic of experimental Configuration: 1. Water reservoir, 2. Water pump, 3. Flow meter, 4. Membrane module, 5. DO meter, 6. Pressure transducer, 7. Personal computer.

\subsection{RESULTS AND DISCUSSION}

The mass transfer performance obtained experimentally were analyzed using model developed by Ahmed and Semmens [9]. Equation (11) were used to analyze the overall mass transfer coefficients, depending on the concentration profile of DO in the water reservoir, volume of water in the reservoir, liquid flow rate, membrane area and fibers length in the module. Experiments were repeated three times for each liquid velocity and an average was obtained to ensure the reading and to minimize the experimental errors.

Oxygen flux through the membrane contactors, $J_{\mathrm{O} 2}$, and the overall mass transfer coefficients, $K$, from the experimental results were plotted versus water velocity, $v_{1}$, as shown in Figure 2 and 3 , respectively. As it can be seen from Figure 2, the sealed end hollow fiber membrane contactor can remove dissolve oxygen from water as high as 3.4-gram oxygen per square meter membrane area per hour. The oxygen flux decreases with increasing module-packing density for the same water velocity. The same effect also occurred for the mass transfer coefficient of the membrane contactors. The lower the packing density of the unconfined sealed end hollow fiber module used in the experiments, the better the contact between the fibers and the water as the fibers more fluidized at lower packing 


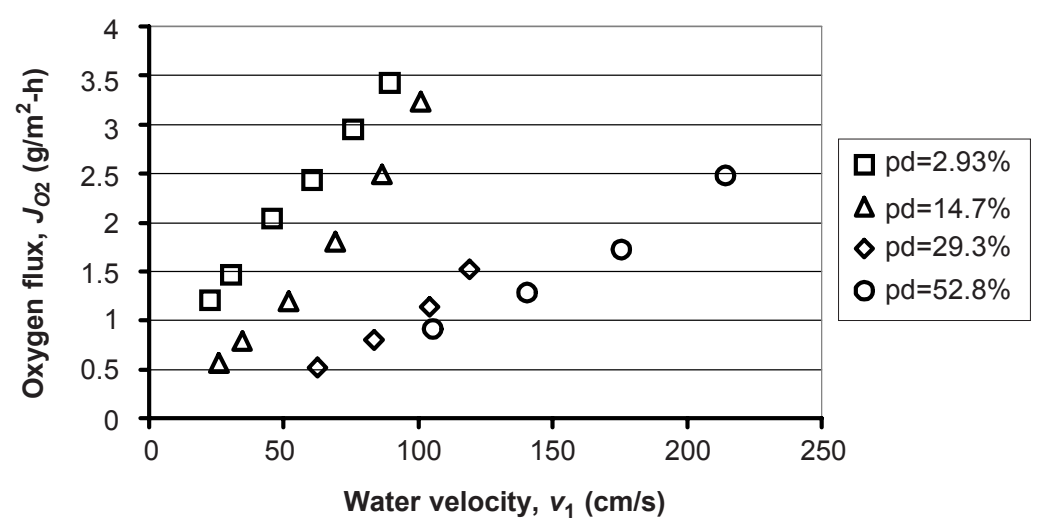

Figure 2 Variation of flux of oxygen trough the membrane contactor $J_{O 2}$ with water velocity $v_{1}$ at various module packing densities and module diameter, $d_{p}=1.2 \mathrm{~cm}$

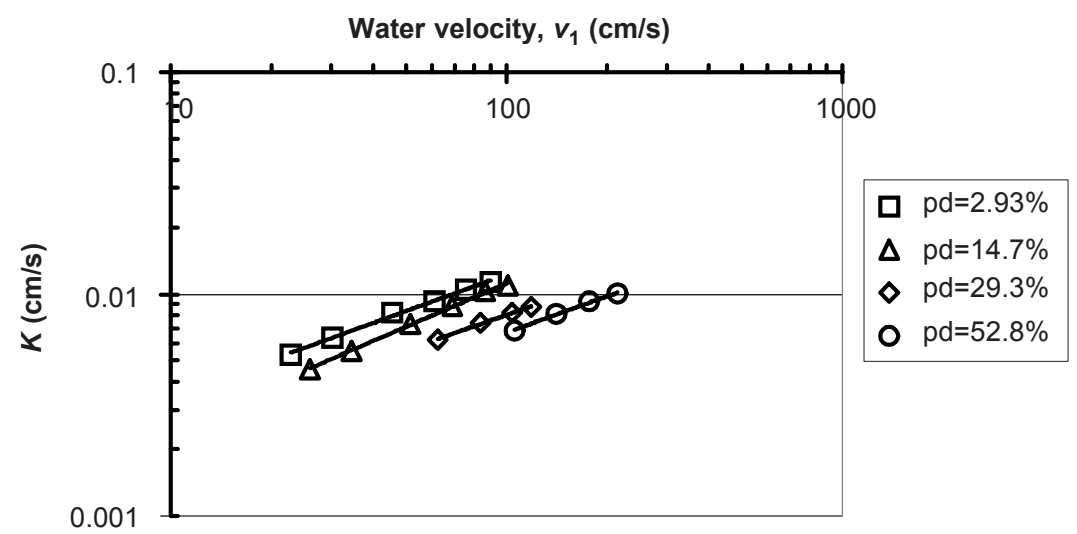

Figure 3 Variation of mass transfer coefficient $K$ with water velocity $v_{1}$ at various module packing densities and module diameter, $d_{p}=1.2 \mathrm{~cm}$

density. In a region of low packing density, module transverse flow and surface renewal effect is seem to be more influence the mass transfer performance rather than channeling effect, meanwhile at the higher packing density, the channeling effect is more dominant [10]. From another point of view, the geometrical dependencies of boundary layer profiles might also increase the mass transfer coefficient of module with lower packing density. The increase is directly related to the boundary layer conditions, where the profiles of boundary layers on a curved body become thinner with an increasing degree of curvature, as for example decreasing $d_{o}$ fiber with other conditions constant. The effect has further strengthened by the fluidized fibers in the module to create the renewal effect on the mass transfer performance. Therefore, based on this theory, the mass transfer coefficient will increase with decreasing packing density of the module, especially at higher liquid velocities. The channeling occurred because of the existing regions of densely- and loosely-packed in the module which creates preferential flow around fibers in the module resulted mainly from uneven distribution of fibers and flow [10]. Membrane contact area might have been reduced in densely packed regions as fibers were more adhered to each other, reducing the availability of contacting surface. 
To examine the dependence of oxygen transfer coefficient on the process parameters, correlation are conveniently expressed in terms of dimensionless Sherwood number, $S h$, Reynolds number, $R e$, and Schmidt number, $S c$. General equation to correlate these parameters are expressed by Equation (3), and for oxygen-water system the term $\left(d_{h} / l\right)$ can be neglected [6] so that Equation (3) can be reduced into Equation 12,

$$
S h=A R e^{B} S c^{C}
$$

In this study, the Schmidt number, $S c$, was not varied, so the $1 / 3$ power-dependence in the literature was assumed, and Equation (12) become

$$
S h=A R e^{B} S c^{0.33}
$$

Figure 4 shows the experimental data as $S h$ plotted against $R e$ at various packing densities to obtain the exponent for Reynolds number, $B$ in Equation (12) for each module. For the module consists of 100 fibers and 80 fibers, experiments were also conducted at low liquid flow rate to examine the mass transfer performance at lower Reynolds numbers. Furthermore, Equation (12) can be simplified into Equation (14) to see the dependency of Reynolds number on mass transfer performance.

$$
S h=a \operatorname{Re}^{b}
$$

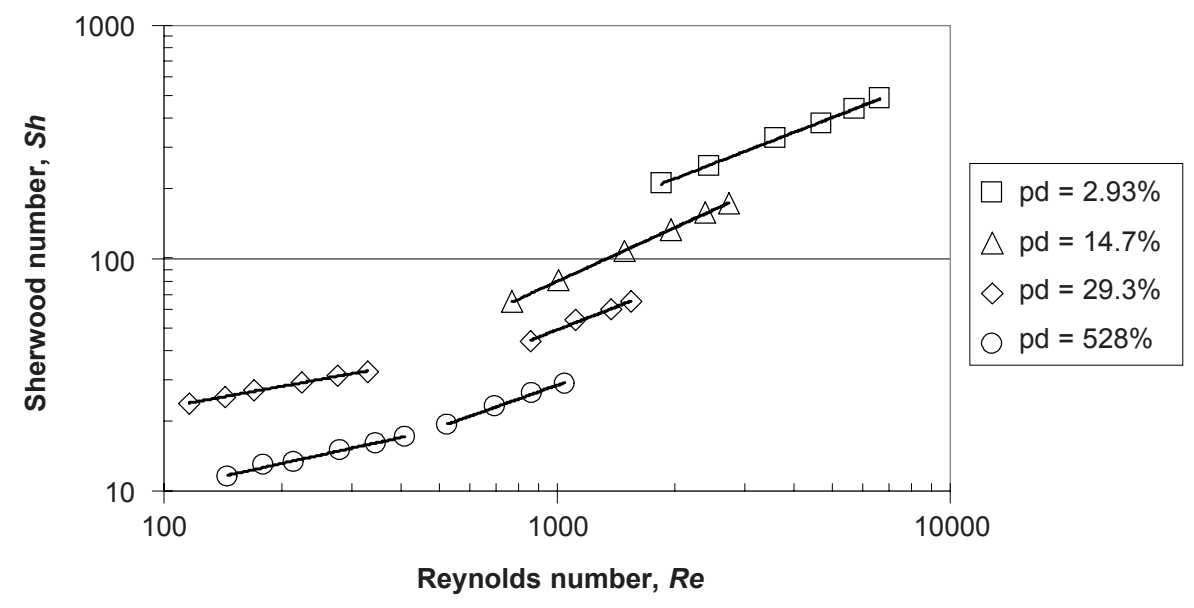

Figure 4 Plot of Sherwood number $S h$ versus Reynolds number $R e$ at various module packing densities and module diameter, $d_{p}=1.2 \mathrm{~cm}$ and $0.8 \mathrm{~cm}$

Figure 4 shows that the mass transfer coefficients data for modules with 100 fibers and 80 fibers fall into two distinct regions so that the mass transfer correlation will be obtained into two Reynolds number regions, those are $R e>400$ and $R e<400$. The exponent for Reynolds number, $B$, was obtained by the linear regression of Figure 4 and it was found that the values were ranging from 0.60 to 0.79 for $R e>400$ and had the average value of $B=0.7$. This value indicated that the mass transfer in the module for $R e>400$ is dominated by turbulent flow. Furthermore, an empirical correlation for mass transfer performance in the sealed end hollow fiber membrane contactors for higher Reynolds number $(R e>400)$ can be correlated in the form, 


$$
\begin{gathered}
S h=A R e^{0.7} S c^{0.33} \\
A=\left(0.1666-0.7978 \varphi+1.7382 \varphi^{2}-1.3701 \varphi^{3}\right)
\end{gathered}
$$

where $\varphi$ is module packing fraction, respectively. Meanwhile, an empirical correlation for mass transfer performance in the sealed end hollow fiber membrane contactors for lower Reynolds number $(\operatorname{Re}<400)$ can be correlated in the form:

$$
S h=0.1789 \varphi^{-0.86} R e^{0.34} S c^{0.33}
$$

The effect of fiber length on mass transfer coefficient in the contactors was evaluated at all parameters affecting the mass transfer coefficients constant except the fiber length. To study this affect, the sealed end module of $1.4 \mathrm{~cm}$ in diameter and consists of 10 fibers of 40, 66 and $86 \mathrm{~cm}$ lengths were used in the experiments and the results were plotted in Figure 5. As can be expected from Equations (15) and (17), the mass transfer coefficients were independent of fiber length. Leikness and Semmens [8] also reported that the fiber length had no effect up to $150 \mathrm{~cm}$. However, the results might be different if the fiber used for comparison is long enough so that the pressure drop in the lumen side cannot be neglected. As it can be expected, the longer the fibers, the higher the pressure

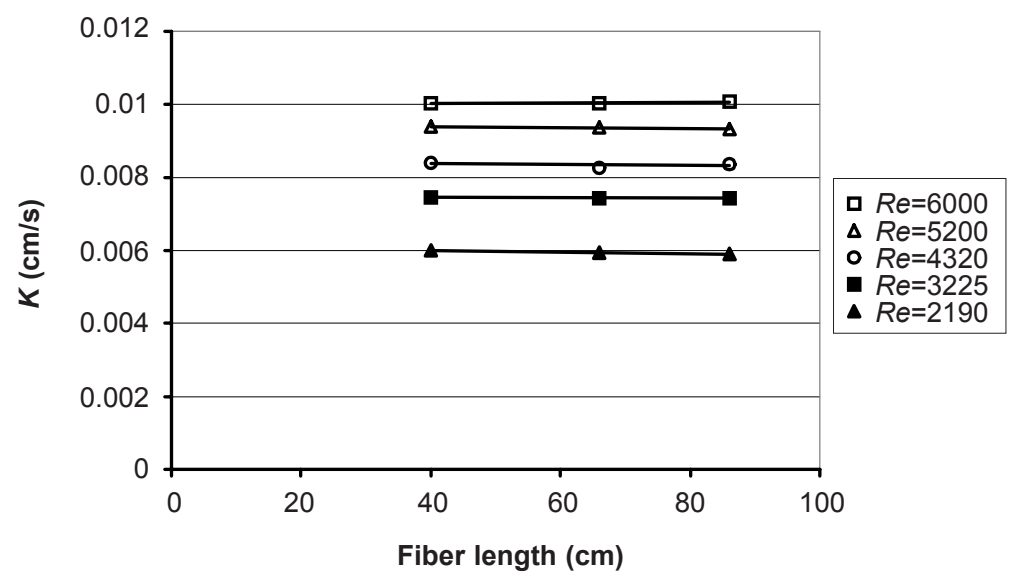

Figure 5 Variation of overall mass transfer coefficients $K$ with fiber length at various Reynolds numbers

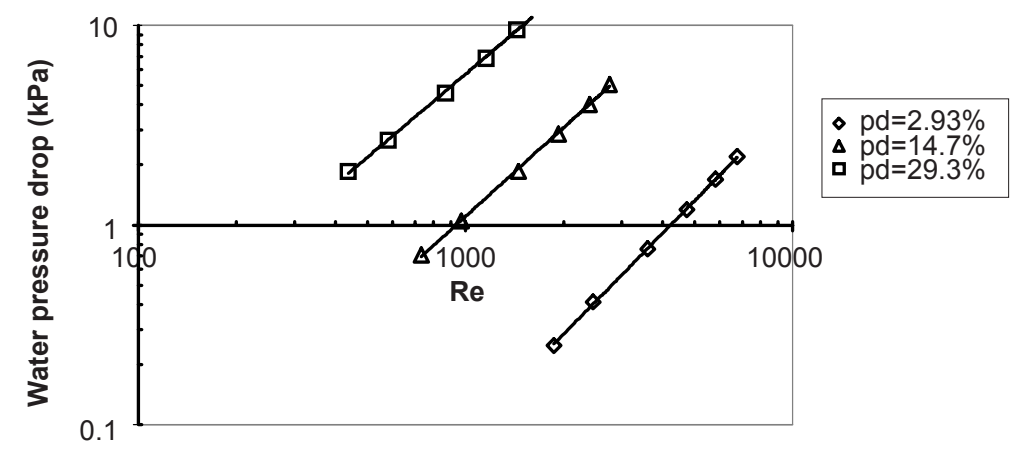

Figure 6 Variation of water pressure drop $\Delta P$ with Reynolds number $R e$ at various module packing densities and module diameter, $d_{p}=1.2 \mathrm{~cm}$ 
drop within the fibers and the lower the driving force for the gas transfer through the fibers, resulting a decrease in mass transfer performance.

The pressure drop was plotted against Reynolds number in Figure 6 to see the effect of flow to the module pressure drop. It is shown in Figure 6 that at the same Reynolds number, pressure drops increase with increasing module-packing density due to an increase in friction between fibers and water. In addition the increase in packing density for the same module diameter will reduce the equivalent diameter $d_{e}$, and available area for water flow, which will increase water velocity at the same Reynolds number, and based on Equation (8), the pressure drop increases with decreasing equivalent diameter of the module and increasing water velocity. The same effect can also be seen from the plot of pressure drop versus water velocity as shown in Figure 7.

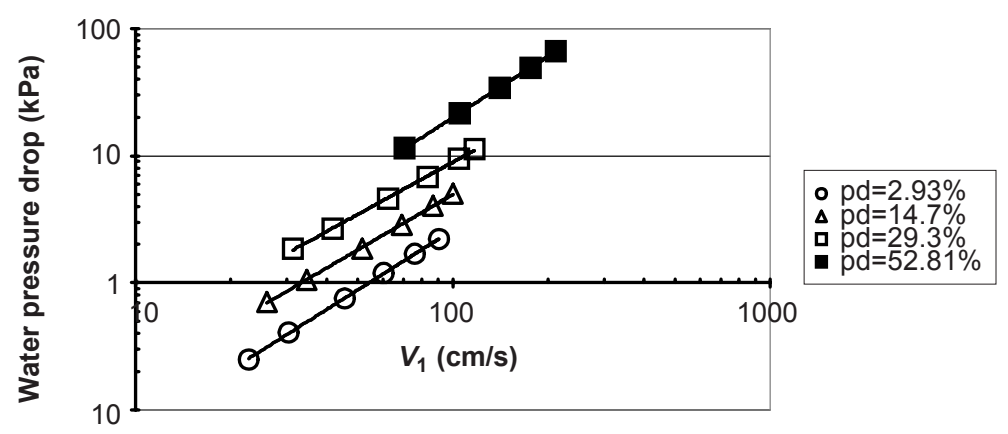

Figure 7 Plots of water pressure drop $\Delta P$ versus water velocity at various module packing densities and module diameter, $d_{p}=1.2 \mathrm{~cm}$ and $0.8 \mathrm{~cm}$

\subsection{CONCLUSIONS}

The study has been conducted to evaluate the performance of sealed end hydrophobic microporous polypropylene (PP) hollow fiber membranes contactors to remove dissolved oxygen from water via vacuum degassing process. Based on the experimental result, the sealed end membrane contactor can remove oxygen from water as high as 3.4-gram oxygen per square meter of membrane area per hour. The oxygen flux decreases with increasing module-packing density for the same water velocity. The same effect also occurred for the mass transfer coefficient of the membrane contactors. The mass transfer was in turbulent region for $R e>400$ and in laminar region for $R e<400$. The mass transfer correlation for $R e>400$ can be expresseed as $S h=\left(0.1666-0.7978 \varphi+1.7382 \varphi^{2}-3701 \varphi^{3}\right)$ $R e^{0.7} S c^{0.33}$. Meanwhile, the mass transfer correlation for $R e<400$ can be expressed as $S h=0.1789 \varphi^{0.86}$ $R e^{0.34} \mathrm{Sc}^{0.33}$. The mass transfer coefficients were independent of fiber length within the range of study. Hydrodynamics analysis of the contactors showed that, at the same Reynolds number, pressure drops increase with increasing packing density due to an increase in friction between fibers and water. The same effect also occured for the same water velocity.

\section{NOMENCLATURE}

$\begin{array}{ll}a & \text { surface area to volume ratio }\left[\mathrm{m}^{2} \mathrm{~m}^{-3}\right] \\ A & \text { geometry exponent } \\ B & \text { empirical constant }\end{array}$


$B \quad$ Reynolds number exponent

C Schmidt number exponent

$C_{0} \quad$ initial water phase oxygen concentration in the reservoir $\left[\mathrm{kgm}^{-3}\right]$

$C_{t} \quad$ water phase oxygen concentration in the reservoir at time $t\left[\mathrm{kgm}^{-3}\right]$

$d_{e} \quad$ equivalent diameter $[\mathrm{m}]$

$d_{p} \quad$ module shell diameter [m]

$D \quad$ diffusivity of oxygen in water $\left[\mathrm{m}^{2} \mathrm{~s}^{-1}\right]$

$f \quad$ friction factor

$K \quad$ overall mass transfer coefficient $\left[\mathrm{ms}^{-1}\right]$

$k_{g}, k_{m}, k_{l}$ individual mass transfer coefficient of gas, membrane and water, respectively [ms ${ }^{-1}$ ]

$l \quad$ fiber length $[\mathrm{m}]$

$n \quad$ number of fiber

$Q_{l} \quad$ liquid flow rate $\left[\mathrm{m}^{3} \mathrm{~s}^{-1}\right]$

Re Reynolds number

Sc Schmidt number

Sh Sherwood number

$t$ time

$v \quad$ velocity $\left[\mathrm{ms}^{-1}\right]$

$V \quad$ volume of water in the reservoir

\section{GREEK LETTERS}

$\varphi \quad$ packing fraction

$v \quad$ kinematics viscosity $\left[\mathrm{m}^{2} \mathrm{~s}^{-1}\right]$

$\rho \quad$ pensity $\left[\mathrm{kgm}^{-3}\right]$

$\Delta P \quad$ water pressure drop [Kpa]

\section{REFERENCES}

[1] Gabelman, A. and S. T. Hwang. 1999. Hollow Fibre Membrane Contactors. J. Membr. Sci. 159: 61-106.

[2] Juang, R.-S., S.-H. Lin and M.-C. Yang. 2005. Mass Transfer Analysis on Air Stripping of VOCs from Water in Microporous Hollow Fibers. J. Membr. Sci. 255: 79-87.

[3] Bhaumik, D., M. Sudipto, F. Qiuxi and K. K. Sirkar. 2004. Hollow Fiber Membrane Degassing in Ultrapure Water and Micro-biocontamination. J. Membr. Sci. 235: 31-41.

[4] Ito, A., K. Yamagiwa, M. Tamura, and M. Furusawa. 1998. Removal of Dissolved Oxygen Using Non-porous Hollow-fibre Membranes. J. Membr. Sci. 145: 111-117.

[5] Li, K., I. Chua, W. J. Ng, W. K. Teo. 1995. Removal of Dissolved Oxygen in Ultra Pure Water Production Using a Membrane Reactor. Chem. Engin. Sci. 50(22): 3547-3556.

[6] Costello, M. J., A. G. Fane, P. A. Hogan, and R. W. Schofield. 1993. The Effect of Shell Side Hydrodynamics on the Performance of Axial Flow Hollow Fibre Modules. J. Membr. Sci. 80: 1-11.

[7] Ahmed, T. M. J. Semmens, and M. A. Voss. 2000. Energy Loss Characteristics of Parallel Flow Bubbleless Gollow Fibre Membrane Aerators. J. Membr. Sci. 171: 87-96.

[8] Leiknes, T. and M. J. Semmens. 2001. Vacuum Degassing Using Microporous Hollow Fibre Membranes, Separation and Purification Technology. 22-23: 287-294. 
[9] Ahmed, T. and M. J. Semmens. 1992. Used of Sealed End Hollow Fibre for Bubbleless Membrane Aeration: Experimental Studies. J. Membr. Sci. 69: 1-10.

[10] Lipnizki, F., and R. W. Field. 2001. Mass Transfer Performance for Hollow Fibre Modules with Shell-side Axial Feed Flow: Using an Engineering Approach to Develop a Framework. J. Membr. Sci. 193: 195-208.

[11] Wu, J. and V. Chen. 2000. Shell-side Mass Transfer Performance of Randomly Packed Hollow Fibre Modules. J. Membr. Sci. 172: 59-74. 
Determination of A parameter in Equation (16) as a function of packing fraction $\varphi$.

The values of $A$ for each module for $R e>400$ were obtained from the slope of the experimental Sherwood number against $R e^{0.7} S c^{0.33}$ as shown in Figure 8 where these values are ranging from 0.028 to 0.1594 with the assumption that the average experiment temperature is $20^{\circ} \mathrm{C}$. To obtain the correlation between $A$ and packing fraction of the module, the values of $A$ were plotted against module packing fraction as shown in Figure 9. It can be seen from Figure 9 that the correlation between $A$ and packing fraction is best fitted by Equation (16),

$$
A=\left(0.1666-0.7978 \varphi+1.7382 \varphi^{2}-1.3701 \varphi^{3}\right)
$$

where $\varphi$ is packing fraction of the module, respectively.

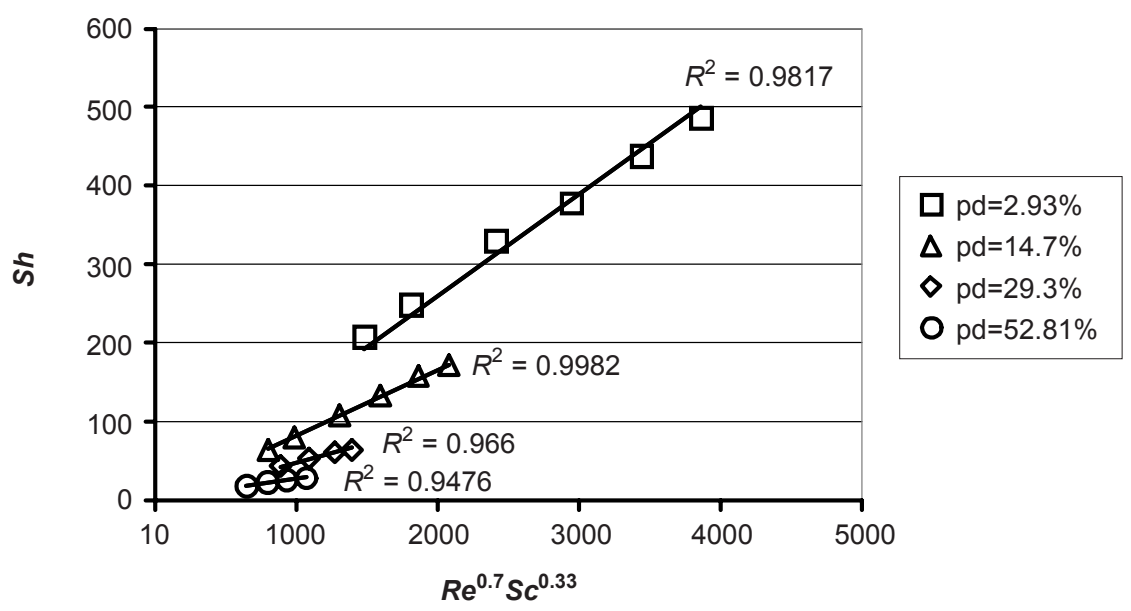

Figure 8 Plot of Sherwood number $S h$ versus $R e^{0.7} S c^{0.33}$ at various module packing densities and module diameter, $d_{p}=1.2 \mathrm{~cm}$ and $0.8 \mathrm{~cm}$

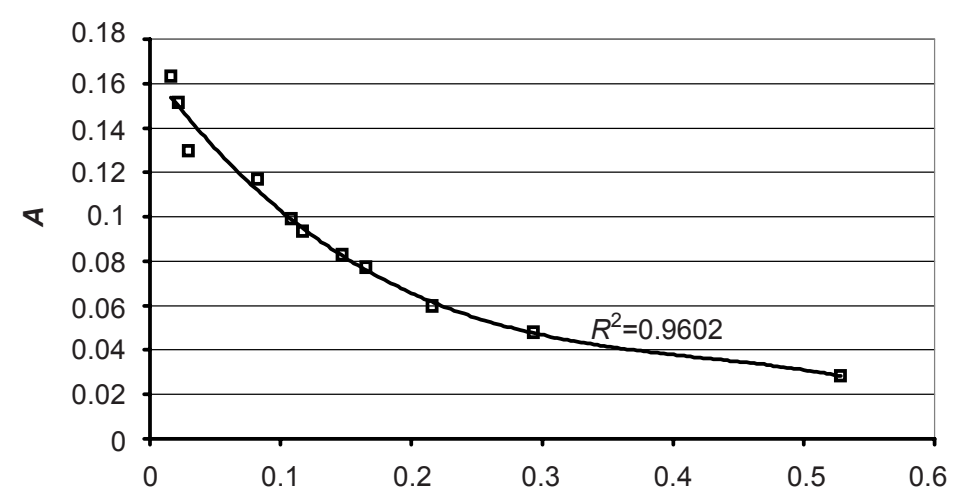

Figure 9 Variation of $A$ with module packing fraction at $R e>400$ to obtain the correlation between coefficient $A$ and module packing fraction, $\varphi$ 